Chapter 12

\title{
Time Series and Renewable Energy Forecasting
}

\author{
Mahmoud Ghofrani and Anthony Suherli
}

Additional information is available at the end of the chapter

http://dx.doi.org/10.5772/intechopen.71501

\begin{abstract}
Reliability is a key important criterion in every single system in the world, and it is not different in engineering. Reliability in power systems or electric grids can be generally defined as the availability time (capable of fully supplying the demand) of the system compared to the amount of time it is unavailable (incapable of supplying the demand). For systems with high uncertainties, such as renewable energy based power systems, achieving a high level of reliability is a formidable challenge due to the increased penetrations of the intermittent renewable sources such as wind and solar. A careful and accurate planning is at the utmost importance to achieve high reliability in renewable energy based systems. This chapter will assess wind-based power system's reliability issues, and provide a case study that proposes a solution to enhance the reliability of the system.
\end{abstract}

Keywords: availability, energy storage, renewable energy, reliability, wind

\section{Introduction}

The world is moving forward in technology as power systems lean toward renewable energy more and more each year. While the idea of using renewable energy has long been the focus of numerous researches from all over the world, the implementation itself is more complicated than said. Dealing with renewable energy proposes new challenges that must be carefully addressed and solved. The uncertainty of renewable energy sources, such as wind speed (for wind turbines) or solar radiation (for solar photovoltaic (PV) panels), and the fact that it is unreliable from time to time due to said uncertainty, are two of the major issues that rough up the transition from fossil based energy sources to renewable energy sources. The main objective of operational and planning strategies is to enable power systems to constantly and continuously meet the consumers' demand or the system load. The volatility of renewable energy sources jeopardizes the power system's ability to reliably meet this objective. 
Climate change concerns, and new state initiatives are some of the factors that contributed in pushing and escalating the number of wind power based technology deployment during recent years. The stochastic nature of wind power resources makes it difficult to perform a reliable operation. While this issue has been frequently studied and numerous methods have been developed, a flawless solution for every case has not yet been designed. One of the proposed solutions is to use fast-responding units like gas generators as the operating reserves to keep up with the demand [1, 2], although doing that reduces the system's efficiency and increases its operating costs [3]. Another possible solution is to install energy storage systems, which store wind power during low-demand periods and release power during periods when the system cannot provide sufficient power to meet the load [4]. This increases the flexibility of the power system as the energy storage system counterbalances the unexpected wind power fluctuations to more efficiently utilize the smoothened wind power for supplying the system demand.

In the upcoming future, energy storage systems are expected to be an essential part of electric grids. However, its deployment depends heavily on its economic advantages when compared to the more conventional operational practices. To come up with the most economically beneficial plan, a cost-benefit analysis must be done for each possible technology, especially in regulated utilities where the limited market opportunities diminish the potential economic benefits of storage technologies over gas-fired generators [3]. To assure the effectiveness of an energy storage system, we must approach the problem with an appropriate strategy [5, 6]. An optimal storage sizing strategy furnishes the system with the capability to stabilize against forecast uncertainty and integrate wind power more reliably [7-9], added with optimal scheduling, it also improves the system's transmission capacity utilization.

For high wind penetrations, fast-response thermal units are used as reserve capacities to provide the fast ramping capability required to deal with wind power fluctuations. Recent developments in storage technologies have advanced its energy efficiency and enhanced its capability in dealing with fast ramping. Additionally, storage systems bring forth several benefits when compared to fast-response thermal units, such as efficiency enhancement of renewable integration, reduced emission, and improved utilization of grid assets.

Several applications have been proposed for energy storage systems, which include but are not limited to renewable capacity firming and reliability enhancement of renewable integration. Each application requires a case-by-case optimal allocation strategy, which might result in different solutions. Particularly, the matter of optimally sizing, siting, scheduling and operating storage systems to address the reliability issues of intermittent renewable integration is of great importance. A solid, probabilistic optimization framework is needed to supplement grid operability and reliability while at the same time reduces overall costs for systems with high wind penetrations. The framework developed by the author in Ref. [10] is adopted for this chapter and is provided in the next section. A case study is presented in this chapter to analyze the reliability of renewable energy based systems and compare storage technologies and conventional gas-fired alternatives for reliably integrating different wind penetrations. An economic analysis is also provided to calculate costs and benefits associated with each technology to determine the most economical solution. 


\section{Methodology}

The following methodology is one possible solution example to model an intermittent renewable energy-based power system.

\subsection{Wind, load, and equipment availability modeling}

We use probability distribution functions (PDFs) to model the stochastic nature of load and wind generation, which parameters are calculated using 10 years of historical hourly data for load and wind speed [11]. The produced model will then be used to generate hourly samples for the planning period. We use Fuzzy C-Means (FCM) clustering to capture a statistical model that takes into account seasonal variations [12]. We grade each of the sample points with a value within the range of $[0,1]$, then we minimize the weighted distance between any sample point and a cluster center by using an iterative algorithm. The elbow method determines the total number of clusters [13]. By combining the FCM clustering and the elbow method, we categorize our planning days into 40 clusters of 24-hour wind speed and load samples. We utilize the maximum likelihood method to find the parameters of the PDFs for the samples. Two sets of 24 individual PDFs will represent each of the clusters for a 24-hour period.

\subsubsection{Wind power modeling}

The total power generated by a wind turbine can be calculated by the product of a simple kinetic energy equation through a cross sectional area A as follows [14].

$$
P=\frac{1}{2} \rho v^{3} A=\frac{1}{2} \rho v^{3} \frac{\pi d^{2}}{4}
$$

where $v$ is the wind speed in meters per second $(\mathrm{m} / \mathrm{s}), \rho$ represents air density in $\mathrm{kg} / \mathrm{m}^{3}$ and $d$ is the rotor diameter in meters.

The power output of a wind turbine depends heavily on the speed of the wind, and the wind speed itself can be best characterized by using the Weibull PDF, which formula is the following $[11,15]$ :

$$
f(v ; c, k)=\frac{k}{c}\left(\frac{v}{c}\right)^{k-1} e^{-\left(\frac{v}{c}\right)^{k}}
$$

where $k$ is a shape vector, $c$ is the scale vector, and $v$ is a vector of the measured wind speed. The average width of the wind speed distribution is determined by the shape vector $k$, while the scale vector indicates where the majority of the distribution lies and how wide the distribution-stretch is.

The wind power output can be calculated by using the power-speed curve [16]: 


$$
G_{W}=\left\{\begin{array}{cc}
0 & v \leq v_{i}, v \geq v_{o} \\
\frac{v-v_{i}}{v_{r}-v_{i}} G_{W_{r}} & v_{i} \leq v \leq v_{r} \\
G_{W_{r}} & v_{r} \leq v \leq v_{o}
\end{array}\right.
$$

where $G_{W}$ is the output wind power, and $v_{i}, v_{0}, v_{r}, v$ represents cut-in speed, cut-out speed, rated speed, and wind speed respectively.

\subsubsection{Load modeling}

The variation of the load is described by the Gaussian distribution [11]:

$$
f(l ; \mu, \sigma)=\frac{1}{\sqrt{2 \pi \sigma^{2}}} \exp \left[-\frac{(L-\mu)^{2}}{2 \sigma^{2}}\right]
$$

where $\sigma$ and $\mu$ represent the standard distribution, and mean of the Gaussian distribution respectively, and $L$ represents the load demand.

\subsubsection{Equipment availability modeling}

Forced outage rate $(F O R)$ of an equipment is the unavailability of the equipment estimated for a long-time period [17]. FOR models the availability of the equipment stochastically by the binomial PDF as follows:

$$
f(q ; n, p)=\left(\begin{array}{l}
n \\
q
\end{array}\right) p^{q}(1-p)^{n-q}
$$

where $n$ is the number of units for each power plant and $q=0,1,2, \ldots, n$. The availability of each unit $p$ is:

$$
p=1-F O R
$$

where FOR is basically the probability of the system's unavailability. For systems with long operating cycles, FOR can adequately estimate the unavailability probability of units that operates under similar conditions. On the other hand, it is not an adequate estimator for systems with short demand cycles. The most important period in the operation of a unit is the start-up period, and a peaking unit (example of a system with short demand cycles) will have less operating hours with more start-up and shut-down periods [17].

\subsection{Energy storage modeling}

The model of a storage system must be able to handle the energy balance between the sum of the stored and generated energy and the load, where it stores excess energy gained from wind generation and releases the energy to supply the peak demand. We can use compressed air energy storage (CAES) to enhance the wind integration performance in a transmission 
network due to its beneficial features such as large power capacity, long lifetime, and low operation costs [18]. The charging and discharging equations of the storage system are as follows:

$$
\begin{array}{ll}
S_{t}=\left(1-d_{s}\right) S_{t-1}+\eta_{c s} L_{s_{t}} & \forall t \in T \\
S_{t}=\left(1-d_{s}\right) S_{t-1}-\eta_{d s} G_{s_{t}} & \forall t \in T
\end{array}
$$

where $S_{t}$ represents the energy stored in the storage system at hour $\mathrm{t}, \eta_{c s}$ and $\eta_{d s}$ represents the charging and discharging efficiencies for the CAES, $L_{s_{t}}$ represents the storage loading capacity at hour $\mathrm{t}$, and $G_{s_{t}}$ represents the storage generating capacity at hour $\mathrm{t}$, and $d_{s}$ represents the self-discharge rate for CAES.

The state of charge of the storage system at any time $t$ is within the minimum and maximum storage capacity requirements:

$$
S_{\min } \leq S_{t} \leq S_{\max } \quad \forall t \in T
$$

where $S_{\min }$ and $S_{\max }$ are the minimum and maximum storage capacities.

The stored power must not exceed the maximum power rating at any given time as follows:

$$
\left|P_{t}\right| \leq P_{\max } \forall t \in T
$$

where $P_{t}$ and $P_{\max }$ are the storage power at time $\mathrm{t}$ and the maximum storage power respectively.

The following is the ramping constraints for the storage:

$$
\begin{array}{lc}
G_{S_{t}}-G_{S_{t-1}} \leq R U_{s} & \forall t \in T \\
G_{S_{t-1}}-G_{S_{t}} \leq R D_{s} & \forall t \in T
\end{array}
$$

where $R U_{s}$ and $R D_{s}$ are the ramp up and ramp down of the turbine for the storage system respectively.

CAES has an expected lifetime of 30 years [19].

\subsection{Economic modeling}

The storage cost is the sum of the energy and power costs associated with each energy storage technology. The storage cost is described by the following equation [20, 21]:

$$
I C_{S}=C_{S} \cdot S_{\max }+C_{P} \cdot P_{\max }
$$

where $I C_{S}$ is the cost of investment for the storage system, $C_{S}$ is the energy cost for the storage system, and $C_{P}$ is the power cost for the storage system. 
The energy cost for CAES is $53 \$ / \mathrm{kWh}$, which includes the combined reservoir and the balance of plant costs. The power cost of CAES is around $425 \$ / \mathrm{kW}$ [20], which includes turbine, compressor, and other power related costs.

The operation expenses are the sum of operation and maintenance (O\&M) and fuel costs, which can be described by the following equation [22]:

$$
O C_{S_{t}}=H R \cdot G_{S_{t}} \cdot C_{N G_{t}}+C_{O M} \cdot P_{\max } \quad \forall t \in T
$$

where $O C_{S_{t}}$ is the operation cost of the storage system, $H R$ is the turbine heat rate for the storage system, $C_{N G_{t}}$ is the cost of natural gas of the storage system, and $C_{O M}$ represents the cost of operation and maintenance for the storage.

$C_{N G_{t}}, C_{O M}$, and $H R$ are $4300 \mathrm{Btu} / \mathrm{kWh}, 5$ \$MBtu and $2.5 \$ / \mathrm{kW}$-year [20, 22].

For a gas-fired conventional generator, the investment cost and heat rate are $695 \$ / \mathrm{kW}$ and $8000 \mathrm{Btu} / \mathrm{kWh}$ respectively.

The total annual cost can be calculated by uniformly distributing the investment costs over the lifetime as follows:

$$
A=\frac{d(1+d)^{N}}{(1+d)^{N+1}-1} \cdot I C
$$

where $A$ is the annual equivalent cost for the investment, $d$ is the discount rate, $N$ is the life cycle of the investment, and IC is the investment cost.

We assume a discount rate of $10 \%$ and a lifetime of 30 years for the investment.

\subsection{DC optimal power flow}

We use optimal power flow (OPF) to find the steady state condition that at the same time minimizes the total operation and reliability costs. The objective function of the deterministic $\mathrm{OPF}$ is as follows:

$$
\begin{aligned}
\text { Obj.Function } & =\operatorname{Min}\left\{\sum_{i=1}^{n_{g}}\left(a_{i} P_{g_{i, t}}{ }^{2}+b_{i} P_{g_{i, t}}+c_{i}\right)\right. \\
& \left.+\sum_{i=1}^{n_{b}} I E A R_{i} \times I L_{i, t}\right\} \\
& =\operatorname{Min}\left(O C_{t}+I L C_{t}\right) \quad \forall t \in T
\end{aligned}
$$

where $I E A R_{i}$ is the interrupted energy assessment rate at each bus. $a_{i}, b_{i}$ and $c_{i}$ are the coefficients of the cost function for the ith generator, $P_{g_{i, t}}$ represents the power output of the i-th generator at hour $\mathrm{t}$, and ILC is the interrupted load cost.

The objective function above is subject to each of the following constraints: 
Power balance equation:

$$
\sum_{i=1}^{n_{b}} P_{g_{i, t}}=\sum_{i=1}^{n_{b}} P_{d_{i, t}} \quad \forall t \in T
$$

where $P_{d_{i, t}}$ is the supplied load at bus i at hour $t$, and $n_{b}$ is the bus number.

Power generation and load limitations:

$$
\begin{array}{ll}
P_{g_{i, t}}^{\min } \leq P_{g_{i, t}} \leq P_{g_{i, t}}^{\max } & \forall t \in T \\
P_{g_{i, t}}^{\min } \leq P_{g_{i, t}} \leq P_{g_{i, t}}^{\max } & \forall t \in T
\end{array}
$$

where $P_{g_{i, t}}^{\min }$ and $P_{g_{i, t}}^{\max }$ are the lower and upper generation limits for the $\mathrm{i}$-th generator at hour $\mathrm{t}$ respectively.

Interrupted load:

$$
I L_{i, t}=P_{D_{i, t}}-P_{d_{i, t}} \quad \forall t \in T
$$

where $P_{D_{i, t}}$ is the load demand at bus $i$ at hour $\mathrm{t}$.

Generation ramp up and ramp down:

$$
\begin{aligned}
& P_{g_{i, t}}-P_{g_{i, t-1}} \leq R U_{i} \quad \forall t \in T \\
& P_{g_{i, t-1}}-P_{g_{i, t}} \leq R D_{i} \quad \forall t \in T
\end{aligned}
$$

And the transmission line limitation:

$$
\sum_{i=1}^{n_{b}} H_{r-i} \times\left(P_{g_{i, t}}-P_{d_{i, t}}\right) \leq \overline{f_{r}} r \in \Omega \& \forall t \in T
$$

where $H_{r-i}$ is the generalized distribution factor of line $r$ with respect to bus $\mathrm{i}, \overline{f_{r}}$ is the maximum transmission capacity for line $r$, and $\Omega$ is the set of transmission lines.

\subsection{Probabilistic optimal power flow}

A probabilistic OPF is a more appropriate approach when dealing with uncertainties of loads and wind power fluctuations, which process includes running the deterministic power flow continuously to account for the majority of possible system states. This chapter utilizes an approximate method called Hong's point estimate method ( $2 \mathrm{~m}+1$ scheme) to characterize uncertainties, which uses the first few front most statistical moments of stochastic variables to approximate the probability functions [23]. 
$K$ is the number of concentration points that we use to represent the statistical information of the random input variable in our $K \times m$ scheme. A location $x_{i, k}$ and a weight $w_{i, k}\left(x_{i, k}, w_{i, k}\right)$ represent the kth concentration of the random variable $x_{i}$. In order to relate the input and output variables to each other, we apply the non-linear function $F\left(x_{1}, x_{2}, \ldots, x_{i}, \ldots, x_{m}\right)$. The location of the kth value of variable $x_{i}$ is determined by the following equation:

$$
x_{i, k}=\mu_{x_{i}}+\xi_{i, k} \sigma_{x_{i}}
$$

where $\mu_{x_{i}}$ is the mean for the input variable $x_{i}, \xi_{i, k}$ represents the standard location for the input variable $x_{i}$, and $\sigma_{x_{i}}$ is the standard deviation for the input $x_{i}$. We assign a weighing factor $w_{i, k}$ to the current random output variable of the kth concentration. To determine $\xi_{i, k}$ and $w_{i, k}$, for the kth concentration of $x_{i}$, we use the following equations [23]:

$$
\begin{gathered}
\sum_{k=1}^{K} w_{i, k}=\frac{1}{m} \\
\sum_{k=1}^{K} w_{i, k}\left(\xi_{i, k}\right)^{j}=\lambda_{i, j}=1, \ldots, 2 K-1
\end{gathered}
$$

$\lambda_{i, j}$ in the equation above represents the jth standard central moment for the random variable $x_{i}$, and its probability density function $f_{x_{i}}$ can be described as:

$$
\lambda_{i, j}=\frac{M_{j}\left(x_{i}\right)}{\left(\sigma_{x_{i}}\right)^{j}}
$$

The jth central moment of the random variable $x_{i}$ is given by:

$$
M_{j}\left(x_{i}\right)=\int_{-\infty}^{\infty}\left(x_{i}-\mu_{x_{i}}\right)^{j} f_{x_{i}} d x_{i}
$$

Once we obtain every concentration $\left(x_{i, k}, w_{i, k}\right)$, we use the nonlinear function $\mathrm{F}$ to calculate the vector of random output variables $Z(i, k)$ for each point $\left(\mu_{x_{1}}, \mu_{x_{2}}, \ldots, x_{i, k}, \ldots, \mu_{x_{m}}\right)$ as follows:

$$
Z(i, k)=F\left(\mu_{x_{1}}, \mu_{x_{2}}, \ldots, x_{i, k}, \ldots, \mu_{x_{m}}\right)
$$

By using the values from $Z(i, k)$, and the weighing factors, the jth moments of the random output variables can be approximated by:

$$
E\left[Z^{j}\right] \cong \sum_{i=1}^{m} \sum_{k=1}^{K} w_{i, k}(Z(i, k))^{j}
$$

We can extract the desired statistical information of our random output variable using a $2 \mathrm{~m}+1$ scheme by solving (25) for $\mathrm{K}=3$ and $\xi_{i, 3}=0$. The standard locations and weight produced by the equation are: 


$$
\begin{gathered}
\xi_{i, k}=\frac{\lambda_{i, 3}}{2}+(-1)^{3-k} \sqrt{\lambda_{i, 4}-\frac{3}{4} \lambda_{i, 3}{ }^{2}} k=1,2 \xi_{i, 3}=0 \\
w_{i, k}=\frac{(-1)^{3-k}}{\xi_{i, k}\left(\xi_{i, 1}-\xi_{i, 2}\right)} k=1,2 \\
w_{i, 3}=\frac{1}{m}-\frac{1}{\lambda_{i, 4}-\lambda_{i, 3}{ }^{2}}
\end{gathered}
$$

$\lambda_{i, 3}$ and $\lambda_{i, 4}$ are the skewness and kurtosis of $x_{i}$.

The scheme above sets up $\xi_{i, 3}=0$, which results in $x_{i, k}=\mu_{x_{i}}$ in (25), and yields $\mathrm{m}$ of the $3 \mathrm{~m}$ locations at the same point. By that done, it only requires one additional function evaluation for this particular location to complete 1 iteration of our probabilistic OPF. We update the corresponding weight to $w_{0}$ as follows:

$$
w_{0}=\sum_{i=1}^{m} w_{i, 3}=1-\sum_{i=1}^{m} \frac{1}{\lambda_{i, 4}-\lambda_{i, 3}{ }^{2}}
$$

The deterministic DC-OPF is executed $2 \mathrm{~m}+1$ times in order to take all the random variables into account.

\subsection{Reliability analysis}

Reliability analysis provides an index to measure the degree of supply availability to meet the system demand. In the times when generated and stored energy is insufficient to supply the load, load is interrupted to maintain the power balance in the system. Load and generation variations as well as equipment failures are among the system uncertainties that could contribute to the load interruption in a power system. For wind turbines, the reliability model is a combination of a two-state model and power output model defined by (3). This combination is illustrated in Figure 1 to provide the reliability model for wind generators.

The interrupted load in the system is equivalent to the amount of energy that is not supplied for each hour of the scheduling period, which can be described as:

$$
E N S_{t}=\sum_{i=1}^{n_{b}} I L_{i, t} \quad \forall t \in T
$$

where $E N S_{t}$ is the energy not supplied at hour $\mathrm{t}$, and $I L_{i, t}$ is the interrupted load at bus $i$ at hour $t$.

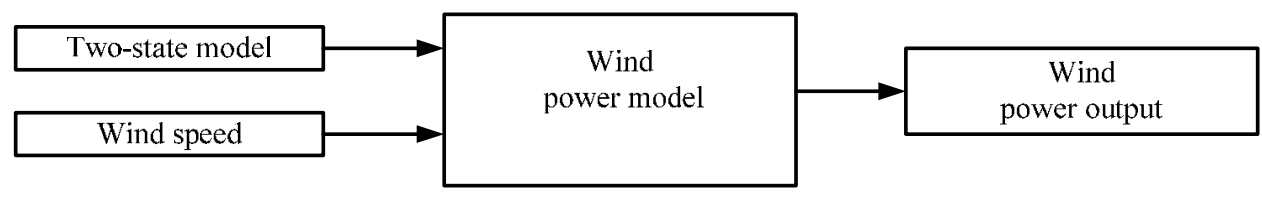

Figure 1. Reliability model for wind generator. 
The interrupted load is defined as a random output variable whose first moment is calculated by (30), with $\mathrm{j}=1$. Expected energy not supplied (EENS) is then calculated for a one-year planning duration to provide a probabilistic index for our reliability analysis.

$$
E E N S=\sum_{c=1}^{C} \sum_{t=1}^{T} \sum_{i=1}^{n_{b}} E\left(I L_{i, t}^{c}\right) \cdot n_{c}
$$

where $n_{c}$ is the number of days within cluster $\mathrm{c}, \mathrm{C}$ is the total number of clusters, $\mathrm{c}$ is the cluster number, and $\mathrm{E}$ is the average function.

We use the energy index of reliability (EIR) to estimate the reliability of the system, which can be calculated as follows:

$$
E I R=1-\frac{E E N S}{E E}
$$

$E E$ represents the expected energy demand of the system during the planning interval and is defined as:

$$
E E=\sum_{c=1}^{C} \sum_{t=1}^{T} \sum_{i=1}^{n_{b}} P_{D_{i, t}}^{c} \cdot n_{c}
$$

\subsection{Genetic algorithm optimization}

We use a Genetic Algorithm (GA)-based optimization to install the energy storage with its optimal location and size. The GA begins by initially taking a set of randomly selected solutions, and then ranking the solutions based on their fitness values. We then perform recombination, crossover, selection, and mutation, to evolve the solution population. Once the satisfaction criterion is satisfied, we put the process into a halt. We assign a large penalty factor to the violated constraint to ensure satisfying constraints.

\subsection{Proposed method}

We model the storage system into our POPF as a load that stores excess, unconsumed energy generated by the system during off-peak periods. The storage system is modeled as a generator to release the stored energy to meet the peak load when sufficient transmission capacity is available. The location and scheduling of the storage systems are then optimized using GA. The optimized solution is the most cost efficient as it minimizes the total operation and interruptedload costs for the span of the planning period. In order to optimally enhance the grid operability for wind integration, the storage technologies must possess an adequate capacity per the system's need. The fitness function that we use for the proposed method is the total weighted sum of the system's cost for each cluster over the planning period, as follows:

$$
\text { Fit.Function }=\operatorname{Min} \sum_{c=1}^{C} \sum_{t=1}^{T}\left(O C_{t}+I L C_{t}\right)_{c} n_{c}
$$


where $O C$ is the operation cost of the system, ILC is the interrupted-load cost of the system, and $n_{c}$ represents the number of days within the cluster.

The proposed GA-based POPF can be described in the following steps:

1. Input wind speed, loads, and FOR data

2. Initialize the first population.
A. For $t=1$, until $t=T$ :

3. Initialize the first input variable by setting $i=1$ and $E(Z)=0 \& E\left(Z^{2}\right)=0$

B. For $\mathrm{i}=1$, until $\mathrm{i}=\mathrm{m}$ :

4. Select input random variable $x_{i}$

5. Calculate $\xi_{i, k}, w_{i, k}, \lambda_{i, j}$

6. Initialize $k=1$.

\section{For $k=1$, until $k=3$ :}

7. Calculate $x_{i, k}$

8a. If $G_{W_{t}}>L_{t}$, model the storage as a variable load with the following constraints:

$$
0 \leq L_{S_{t}} \leq \min \left(S_{\max }-\left(1-d_{s}\right) S_{t-1}, P_{\max }\right)
$$

8b. If $G_{W_{t}}<L_{t}$, model the storage as a generator with the following constraints:

$$
0 \leq G_{S_{t}} \leq \min \left(\left(1-d_{s}\right) S_{t-1}-S_{\min }, P_{\max }\right)
$$

9. Run Deterministic OPF using $Z(i, k)=F\left(\mu_{x_{1}}, \mu_{x_{2}}, \ldots, x_{i, k}, \ldots, \mu_{x_{m}}\right)$

10. Calculate $S$ for charging-discharging by using Eqs. (7 and 8 )

11. Calculate $O C_{t}, I L C_{t}$, and $E E N S_{t}$

12. Update raw moments using the following equations:

$$
E(Z)=E(Z)+w_{i, k} Z(i, k) ; E\left(Z^{2}\right)=E\left(Z^{2}\right)+w_{i, k}[Z(i, k)]^{2}
$$

13. If $k=3$, go to step 14 , if not, go to step $\mathrm{C}$ with $k=k+1$.

14. If $i=\mathrm{m}$, go to step 15, if not, go to step $\mathbf{B}$ with $i=i+1$.

15. If $\mathrm{t}=\mathrm{T}$, go to step 16, if not, go to step A with $t=t+1$.

16. Evaluate the fitness function and constraints

17. Generate children by using crossover and mutation

18a. If termination criteria are not met, produce next generation by selection and combination and go to step 2 .

18b. If termination criteria are met, calculate the statistical output information. 


\section{Case study}

We evaluate our proposed method by applying it on the IEEE 24-bus system with the goal of solving for the optimal size and location for the storage units [10,24]. In our simulations, we test our method for different situations by inputting different wind penetrations. To take into account

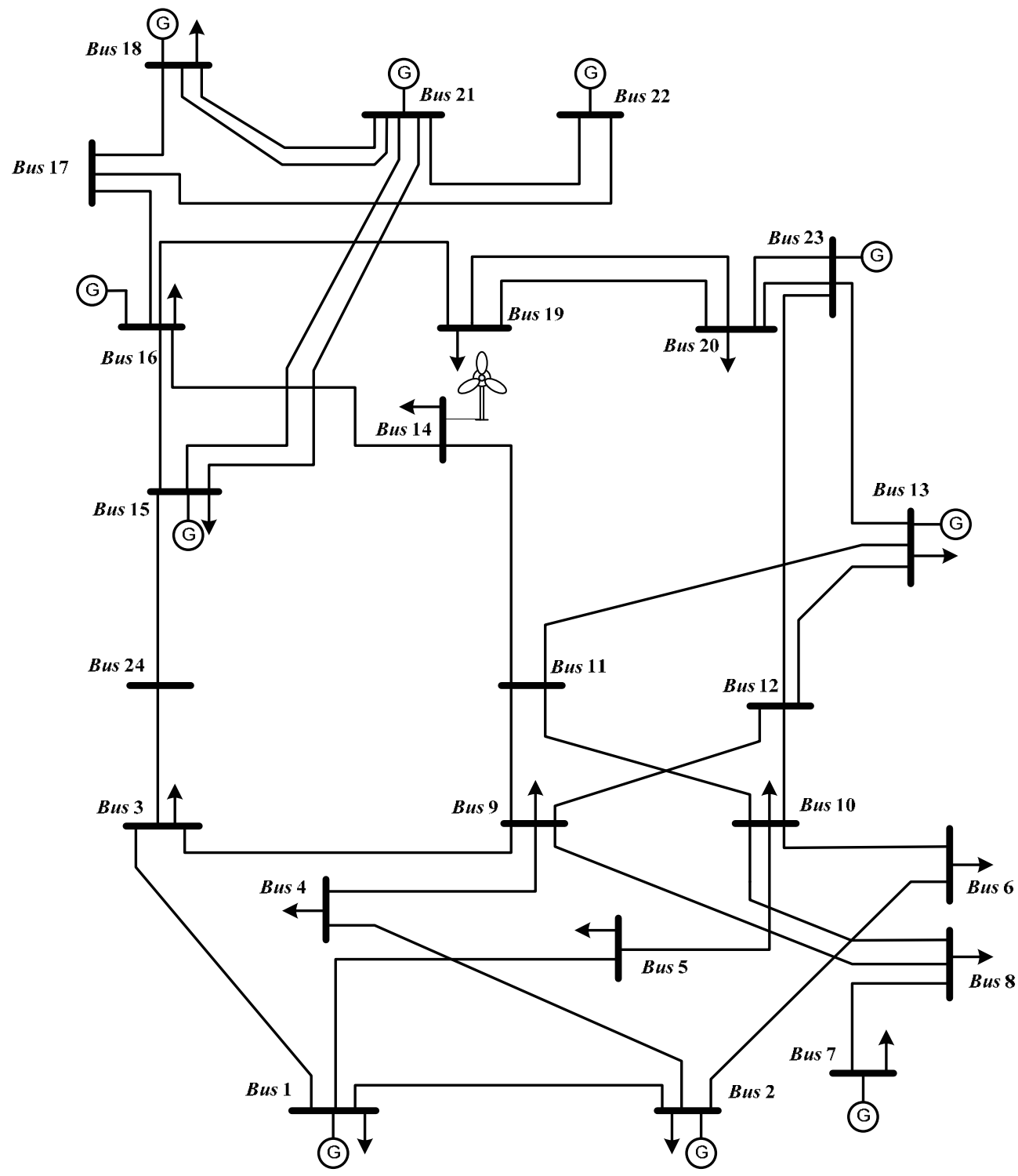

Figure 2. IEEE 24-bus system. 
possible geological restrictions for CAES deployment in a real-world situation, we excluded busses 2, 7, 8, 11, and 17 from candidate locations on purpose. A wind farm is also predeterminedly installed at bus 14 in each of the case studies. A diagram of the IEEE 24-bus system is shown in Figure 2. Tables 1-3 provide more information regarding the flow limitations, generators' cost functions, and IEAR values of the IEEE 24-bus system in use for the case study.

We define wind penetration (WP) as the ratio between the wind capacity installation and the system maximum load. We use real-world historical data obtained from the BPA for the system load [25] and from Mesonet (Ames Station) for the wind speed [26], to create a more realistic simulation environment. To calculate the cost of electric service reliability in the IEEE 24-bus system that we are going to run our demo on, we use the values of IEAR for our load busses [27]. The cost of the storage system, storage cost (SC), is equal to the sum of the cost of investment $(A)$, and its cost of operation $\left(\mathrm{OC}_{\mathrm{s}}\right)$ for the planning period. We can then calculate the cost of conventional generation $(\mathrm{OC})$ by excluding the storage operation cost from the total operation cost.

The objective is to achieve the maximum possible reliability level. Our scenario's goal is to solve for the optimal placement and sizing for the storage system to meet the reliability objective. Our control strategy is to use the available wind energy to supply the load first, followed by utilizing the existing conventional generation capacity, and last, if necessary, to discharge power from the storage system to satisfy the load. The result of the simulations including the comparison with other conventional alternatives is shown in Table 4. Same reliability level is considered for both technologies to make a fair economic comparison. Our storage system, which enhances the reliability of wind integration, can be economically

\begin{tabular}{llllll}
\hline From bus & To bus & Flow limit (MW) & From bus & To bus & Flow limit (MW) \\
\hline 1 & 2 & 175 & 11 & 13 & 500 \\
1 & 3 & 175 & 11 & 14 & 500 \\
1 & 5 & 175 & 12 & 13 & 500 \\
2 & 4 & 175 & 12 & 23 & 500 \\
2 & 6 & 175 & 13 & 23 & 500 \\
3 & 9 & 175 & 14 & 16 & 500 \\
3 & 24 & 400 & 15 & 16 & 500 \\
4 & 9 & 175 & 15 & 21 & 500 \\
5 & 10 & 175 & 15 & 24 & 500 \\
6 & 10 & 175 & 16 & 17 & 500 \\
7 & 8 & 175 & 16 & 19 & 500 \\
8 & 9 & 175 & 17 & 18 & 500 \\
8 & 10 & 175 & 17 & 22 & 500 \\
9 & 11 & 400 & 18 & 21 & 500 \\
9 & 12 & 400 & 19 & 20 & 500 \\
10 & 11 & 400 & 20 & 23 & 500 \\
10 & 12 & 400 & 21 & 22 & 500 \\
\hline
\end{tabular}

Table 1. Transmission flow limitations. 


\begin{tabular}{llll}
\hline Generator & \multicolumn{2}{l}{ Cost function coefficients } & \\
\cline { 2 - 4 } & $\boldsymbol{c}_{i}\left(\$ / M W^{2} h\right)$ & $\boldsymbol{b}_{i}(\$ / M W h)$ & $\boldsymbol{c}_{i}(\$)$ \\
\hline$G_{1}$ & 0.103 & 71.05 & 1313.6 \\
$G_{2}$ & 0.108 & 71.04 & 1168.1 \\
$G_{3}$ & 0.090 & 66.19 & 1078.8 \\
$G_{4}$ & 0.091 & 67.26 & 969.8 \\
$G_{5}$ & 0.078 & 71.60 & 958.2 \\
$G_{6}$ & 0.078 & 71.60 & 958.2 \\
$G_{7}$ & 0.100 & 73.90 & 471.6 \\
$G_{8}$ & 0.090 & 73.90 & 471.6 \\
$G_{9}$ & 0.098 & 69.70 & 445.4 \\
$G_{10}$ & 0.101 & 66.51 & 702.7 \\
\hline
\end{tabular}

Table 2. Coefficients of the cost function for the generators.

\begin{tabular}{lllllllll}
\hline Bus No. & $\mathbf{1}$ & $\mathbf{2}$ & $\mathbf{3}$ & $\mathbf{4}$ & $\mathbf{5}$ & $\mathbf{6}$ & $\mathbf{7}$ & $\mathbf{8}$ \\
\hline IEAR & 6.20 & 4.89 & 5.30 & 5.62 & 6.11 & 5.50 & 5.41 & 5.40 \\
Bus No. & 9 & 10 & 11 & 12 & 13 & 14 & 15 & 16 \\
IEAR & 2.30 & 4.14 & - & - & 5.39 & 3.41 & 3.01 & 3.54 \\
Bus No. & 17 & 18 & 19 & 20 & 21 & 22 & 23 & 24 \\
IEAR & - & 3.75 & 2.29 & 3.64 & - & - & - & - \\
\hline
\end{tabular}

Table 3. IEAR $(\$ / k W h)$ values at each bus in the IEEE bus-system.

evaluated by comparing the sum of its associated costs with the total cost for the conventional alternative. The cost-benefit analysis from our simulation results shows the economic merits of the CAES, which can be found in Table 4.

\section{Conclusions}

Our case study concludes that energy storage technologies are more economic and technically sound options than fossil-fuelled generators to reliably and efficiently integrate intermittent renewable energy such as wind. The merits of energy storage application for reliability enhancement of renewable integration become even more highlighted when the emission costs associated with fossil-fuelled generators are included in the evaluation. This provides the subject of future studies. 


\begin{tabular}{|c|c|c|c|c|c|c|c|c|}
\hline & \multicolumn{2}{|c|}{$\begin{array}{l}20 \% \mathrm{WP} \& 2500 \mathrm{MW} \\
\mathrm{PL}^{*}\end{array}$} & \multicolumn{2}{|c|}{$\begin{array}{l}30 \% \mathrm{WP} \& 3000 \mathrm{MW} \\
\text { PL }\end{array}$} & \multicolumn{2}{|c|}{$\begin{array}{l}40 \% \text { WP \& } 3500 \mathrm{MW} \\
\text { PL }\end{array}$} & \multicolumn{2}{|c|}{$\begin{array}{l}50 \% \text { WP \& } 4000 \mathrm{MW} \\
\text { PL }\end{array}$} \\
\hline & $\mathrm{CS}^{* *}$ & $\mathrm{CA}^{* * *}$ & CS & CA & CS & CA & CS & CA \\
\hline Optimal Placement (Bus \#) & 14 & - & 14 & - & 23 & - & 23 & - \\
\hline$S_{\max }(M W h)$ & 77.81 & - & 778.7 & - & 1524 & - & 1858 & - \\
\hline$P_{\max }(M W)$ & 59.63 & 18.00 & 258.6 & 138.1 & 652.3 & 415.5 & 947.5 & 807.6 \\
\hline $\operatorname{EIR}(\%)$ & 99.80 & 99.80 & 99.28 & 99.28 & 99.03 & 99.03 & 99.19 & 99.19 \\
\hline Wind utilization (\%) & 94.49 & 86.42 & 88.69 & 78.58 & 80.26 & 70.99 & 72.06 & 62.22 \\
\hline OC $\left(10^{9} \$\right)$ & 0.588 & 0.603 & 0.620 & 0.661 & 0.656 & 0.711 & 0.696 & 0.774 \\
\hline GC $\left(10^{9} \$\right)$ & - & 0.002 & - & 0.012 & - & 0.037 & - & 0.077 \\
\hline $\operatorname{ILC}\left(10^{9} \$\right)$ & 0.041 & 0.041 & 0.194 & 0.194 & 0.324 & 0.324 & 0.295 & 0.295 \\
\hline$S C\left(10^{9} \$\right)$ & 0.005 & - & 0.024 & - & 0.053 & - & 0.072 & - \\
\hline \multicolumn{9}{|l|}{$\begin{array}{l}{ }^{*} \text { Peak load. } \\
{ }^{* *} \text { Centralized storage. }\end{array}$} \\
\hline
\end{tabular}

Table 4. Simulation results for different wind penetrations (WP).

\section{Author details}

Mahmoud Ghofrani* and Anthony Suherli

*Address all correspondence to: mrani@uw.edu

Electrical Engineering, Engineering and Mathematics Division, School of STEM, University of Washington Bothell, USA

\section{References}

[1] Kamalinia S, Shahidehpour M, Khodaei A. Security-constrained expansion planning of fast-response units for wind integration. Electric Power Systems Research. 2011;810:107-116

[2] Lee T. Optimal spinning reserve for a wind-thermal power system using EIPSO. IEEE Transactions on Power Systems. 2007;22(1):1612-1621

[3] Denholm P, Ela E, Kirby B, Milligan M, The Role of Energy Storage with Renewable Electricity Generation. Technical Report, NREL/TP-6A2-47187; 2010

[4] Zhao H, Wu Q, Hu S, Xu H, Rasmussen CN. Review of energy storage system for wind power integration support. Applied Energy. 2015;137:545-553 
[5] Gyuk IP, Eckroad S. Energy Storage for Grid Connected Wind Generation Applications. Washington, DC, EPRI-DOE Handbook Supplement, 1008703: U. S. Department of Energy; 2004

[6] Celli G, Mocci S, Pilo F, Loddo M. Optimal integration of energy storage in distribution networks. In: Proc. IEEE PowerTech Conf., Bucharest. 2009

[7] Bludszuweit H, Dominguez-Navarro JA. A probabilistic method for energy storage sizing based on wind power forecast uncertainty. IEEE Transactions on Power Systems. 2011;26(3):1651-1658

[8] Brekken TKA, Yokochi A, Jouanne AV, Yen ZZ, Hapke HM, Halamay DA. Optimal energy storage sizing and control for wind power applications. IEEE Transactions on Sustainable Energy. 2011;2(1):69-77

[9] Dutta S, Sharma R. Optimal storage sizing for integrating wind and load forecast uncertainties. In: Proc. IEEE PES Innovative Smart Grid Technologies (ISGT). 2012

[10] Ghofrani M, Arabali A, Etezadi-Amoli M, Fadala MS. Energy storage application for performance enhancement of wind integration. IEEE Transactions on Power Systems. 2013;28(4)

[11] Zou K, Agalgaonkar AP, Muttaqi KM, Perera S. Distribution system planning with incorporating DG reactive capability and system uncertainties. IEEE Transactions on Sustainable Energy. 2012;3(1):112-123

[12] Arabali A, Ghofrani M, Etezadi-Amoli M, Fadali MS, Baghzouz Y. Genetic- algorithmbased optimization approach for energy management. IEEE Transactions on Power Delivery. 2013;28(1):162-170

[13] Ketchen DJ, Shook CL. The application of cluster analysis in strategic management research: An analysis and critique. Strategic Management Journal. 1996;17:441-458

[14] Arabali A, Ghofarni M, Bassett JB, Moeini-Aghtaie M. Optimum sizing and siting of renewable energy based DG units in distribution systems. Optimization in Renewable Energy Systems: Recent Perspectives; 2017

[15] Nage GD. Analysis of wind speed distribution: Comparative study of Weibull to Rayleigh probability density function; a case of two sites in Ethiopia. American Journal of Modern Energy. 2016;2(3):10-16

[16] Sohoni V, Gupta SC, Nema RK. A critical review on wind turbine power curve modelling techniques and their applications in wind based energy systems. Journal of Energy. 2016;2016:1-18

[17] Billinton R, Allan RN. Reliability Evaluation of Power Systems. 2nd ed; 1984

[18] EPRI-DOE Handbook of Energy Storage for Transmission \& Distribution Applications, EPRI, Palo Alto, CA, and the U.S. Washington, DC: Department of Energy; 2003 
[19] Luo X, Wang J, Overview of Current Development on Compressed Air Energy Storage. EERA Technical Report; 2013

[20] Schoenung SM, Hassenzahl WV, Long- vs. short-term energy storage technologies analysis: A life-cycle cost study: A study for the DOE energy storage systems program. Sandia National Laboratories, SAND2003-2783. 2003

[21] Das T, JD MC. Compressed Air Energy Storage. Ames, Iowa: Iowa State University; 2012

[22] A Report Prepared for Arizona Public Service Company, Study of Compressed Air Energy Storage with Grid and Photovoltaic Energy Generation. Arizona Research Institute for Solar Energy; 2010

[23] Hong HP. An efficient point estimate method for probabilistic analysis. Reliability Engineering and System Safety. 1998;59:261-267

[24] IEEE committee report, a reliability test system. IEEE Transactions on Power Apparatus and Systems. 1989;4(3):1238-1244

[25] Available from: http://transmission.bpa.gov/business/operations/wind/

[26] Available from: http://mesonet.agron.iastate.edu/agclimate/info.phtml

[27] Li Y. Bulk System Reliability Evaluation in a Deregulated Power Industry. A PhD Thesis Submitted to the Department of Electrical Engineering. University of Saskatchewan 
